\title{
СИСТЕМА ЗАБЕЗПЕЧЕННЯ БЕЗПЕКИ ПЕРСОНАЛУ І ПАЦІЄНТІВ У ЛІКАРНЯНИХ ЗАКЛАДАХ: СТРАТЕГІЯ УДОСКОНАЛЕННЯ
}

\author{
О.П. Яворовський ${ }^{1}$, М.М. Риган², О.В. Іванько ${ }^{3}$ Ю.М. Скалецький ${ }^{1,4}$, Р.П. Брухно1, \\ П.М. Михайленко ${ }^{4}$, Т.О. Зінченко ${ }^{1}$, М.І. Бадюк ${ }^{5}$
}

\author{
${ }^{1}$ Національний медичний університет імені О.О. Богомольця, м. Київ, Україна \\ 2Центр спортивної травматології та відновлювальної медицини Національного університету \\ фізичного виховання і спорту України, м. Київ, Україна \\ ${ }^{3}$ КНП «Київська міська клінічна лікарня №1 Виконавчого органу Київської міської ради (КМДА)», \\ м. Київ, Україна \\ ${ }^{4}$ ДУ «Інститут громадського здоров'я ім. О.М. Марзєєва НАМН України», м. Київ, Украӥна \\ 5Українська військово-медична академія, м. Київ, Україна
}

\begin{abstract}
Мета: враховуючи міжнародний досвід оцінити стан інтегрованості питань безпеки пацієнтів $і$ безпеки медичного персоналу у вітчизняних лікарняних закладах та розглянути можливості посилення їх взаємозв'язку і взаємовпливу на користь мінімізації ризиків лікарняного середовища.

Матеріали і методи. Проаналізовані декларації, стратегії ВООЗ, окремих країн, інші документи і тематичні наукові публікації. Досліджено вітчизняну нормативну базу і частково практику формування безпечного лікарняного середовища у 4-х закладах охорони здоров'я (303). Методи досліджень: бібліосемантичний, гігієнічний, системного підходу, аналітичний, статистичні та математичні.

Результати. Оцінено стан інтегрованості питань безпеки пацієнтів і безпеки медичного персоналу у вітчизняних лікарняних закладах. Встановлено, що попередження випадків виробничого травматизму $i$ інцидентів безпеки пацієнтів у вітчизняних лікарняних закладах здійснюється автономно за різними планами та програмами і $є$ неефективним, про свідчить зростання як нещасних випадків у вітчизняних лікарняних закладах, так і стаціонарної та післяопераційної летальності. Запропоновано підходи до трансформації структури і функцій безпекових підрозділів закладів охорони здоров'я з метою формування безпечного лікарняного середовища на засадах культури безпеки.
\end{abstract}

Висновки. Інтеграція питань безпеки пацієнтів та безпеки медичного персоналу у єдиних програмах $\epsilon$ стратегічним напрямом і кращою практикою у формуванні безпечного лікарняного середовища за кордоном і їі доцільно впроваджувати в нашій країні. Вітчизняна нормативна база і практика передбачає автономне та роздільне вирішення безпекових проблем щодо пацієнтів, медичного персоналу і оточуючого середовища. Трансформація структури і функцій підрозділів закладів охорони здоров'я, задіяних у забезпеченні безпеки пацієнтів, медичного персоналу, екологічної безпеки, за єдиною узгодженою стратегією сприятиме формуванню безпечного лікарняного середовища на засадах культури безпеки.

Ключові слова: безпека пацієнтів, безпека і гігієна праці медичного персоналу, інтеграція, заклади охорони здоров'я, культура безпеки.

Вступ. В ядерній енергетиці давно відмітили, що ядерна, технічна, фізична, екологічна безпека, режим гарантій, маючи єдину мету - захист людей, суспільства й навколишнього середовища від радіаційного впливу, спираються практично на єдині принципи забезпечення такого захисту. Більше того, багато елементів або дій мають на меті сприяти підвищенню одночасно різних складових безпеки АЕС, а заходи за одним напрямом підсилюють інші й забезпечують ефект синергізму [1]. Такий комплексний підхід до забезпечення безпеки AEC уже отримав належне нормативне підгрунтя [2]. При цьому синергізм у таких випадках пов'язується 3 формуванням культури безпеки. Під культурою безпеки вважається безпека не як результат контролюючого впливу державних регулюючих органів та окремих підрозділів і посадових осіб організації, а наслідок внутрішньої потреби і особистої зацікавленості у безпеці всіх членів колективу від керівного складу до безпосередніх виконавців виробничих завдань.

Враховуючи досвід атомної енергетики науковці звернули увагу на життєво важливий зв'язок між безпекою медичних працівників та пацієнтів і закликали сектор охорони здоров'я зробити фундаментальні зрушення, щоб прирівняти безпеку працівників до безпеки пацієнтів [3].

Як основний аргумент на користь скоординованого підходу до безпеки в лікарні Braun В. зі співавторами [4] приводить неможливість формування культури безпеки 
при різних підходах до попередження нещасних випадків для пацієнтів і медичних працівників як окремих об'єктів.

Зрештою Спільна комісія з акредитації організацій охорони здоров'я (JCAHO) в США вже близько 15 років вимагає від установ охорони здоров'я створювати плани забезпечення безпечного середовища догляду, котрі мають такі розділи: небезпечні матеріали та відходи, безпека (пацієнтів, членів їх сімей і медичного персоналу), охорона, готовність до надзвичайних ситуацій, безпека життєдіяльності, медичне обладнання, комунальні послуги. В комісії переконані, що реалізація такого плану дозволить мінімізувати ризики в лікарняному середовищі та безпечно керувати медичними закладами.

Прикладом може слугувати план забезпечення безпечного середовища у системі охорони здоров'я університету Ріверсайд (США), мета якого полягає у забезпеченні середовища, яке знижує ризики для пацієнтів, відвідувачів та працівників до прийнятного рівня [5].

Щодо питань єдності безпеки пацієнтів і безпеки персоналу заслуговує на увагу рішення тематичної конференції, організованої Американським коледжем професійних та екологічних наук в охороні здоров'я (ACOEM), яка визнала у якості базового принцип забезпечення безпеки пацієнтів і безпеки персоналу на спільну користь [6]. Для успіху пропонується роботодавцям розпочинати 3 прийняття основних принципів та стратегій, які повинні спиратися на органічний зв'язок між безпекою пацієнтів та охороною праці медичних фахівців, формування нових спільних відносин, єдиних цілей для об'єднання складових безпеки, традиційно відокремлених оперативними центрами їх запровадження i контролю. Автори впевнені, що цьому новому підходу належить майбутнє.

Останні міжнародні декларації [7], а також стратегії з безпеки пацієнтів окремих країн [8-9] і В003 [10] підкреслюють взаємозалежність безпеки пацієнтів і безпеки медичного персоналу, відзначаючи неможливість просування в одній сфері не рухаючись вперед у інших. При цьому наголошується на необхідності працювати над єдиною, всеохоплюючою перспективою системною і підходом для усунення потенційної шкоди як пацієнтам, так i персоналу.

Торкаючись освітніх аспектів безпеки, слід зауважити, що сучасні тематичні підручники з безпеки пацієнтів, приділяють належну увагу й безпеці та гігієні праці персоналу [11].

Сьогодні, в умовах пандемії COVID-19, як ніколи раніше прийшло усвідомлення того, що безпеки пацієнтів не може бути забезпечена без збереження здоров'я медичних працівників [12].

3 іншого ж боку спостерігається така залежність, що чим менше інцидентів безпеки пацієнтів стається, тим менша кількість співробітників страждають від почуття провини, сорому, втрати впевненості у собі i втрати бойового духу [13].

Зважаючи на вище викладений міжнародний досвід ми поставили за мету оцінити стан інтегрованості питань безпеки пацієнтів і безпеки медичного персоналу у вітчизняних лікарняних закладах та розглянути можливості посилення взаємозв'язку і взаємовпливу їх на користь мінімізації ризиків лікарняного середовища.

Матеріали і методи. Проаналізовані декларації, стратегії В003, окремих країн, резолюції i декларації науково-практичних заходів з безпеки пацієнтів, а також тематичні наукові публікації. Досліджено вітчизняну нормативну базу i частково практику формування безпечного лікарняного середовища у 4-х закладах охорони здоров'я (303).

Методи досліджень: бібліосемантичний, гігієнічний, системного підходу, аналітичний, статистичні та математичні.

Результати та їх обговорення.

Існуюча система забезпечення безпеки у 303 (реактивна)

Існуюча структурно-функціональна схема системи забезпечення безпеки і гігієни праці медичних працівників, безпеки пацієнтів у повсякденних умовах та надзвичайних ситуаціях, впливу 303 на довкілля, захищеності пацієнтів, членів їх сімей, медичних працівників, майна представлена на рис. 1, а досліджені нами складові, які характеризують фактичну безпеку лікарняного середовища в обстежених 303, наведені у табл. 1. 


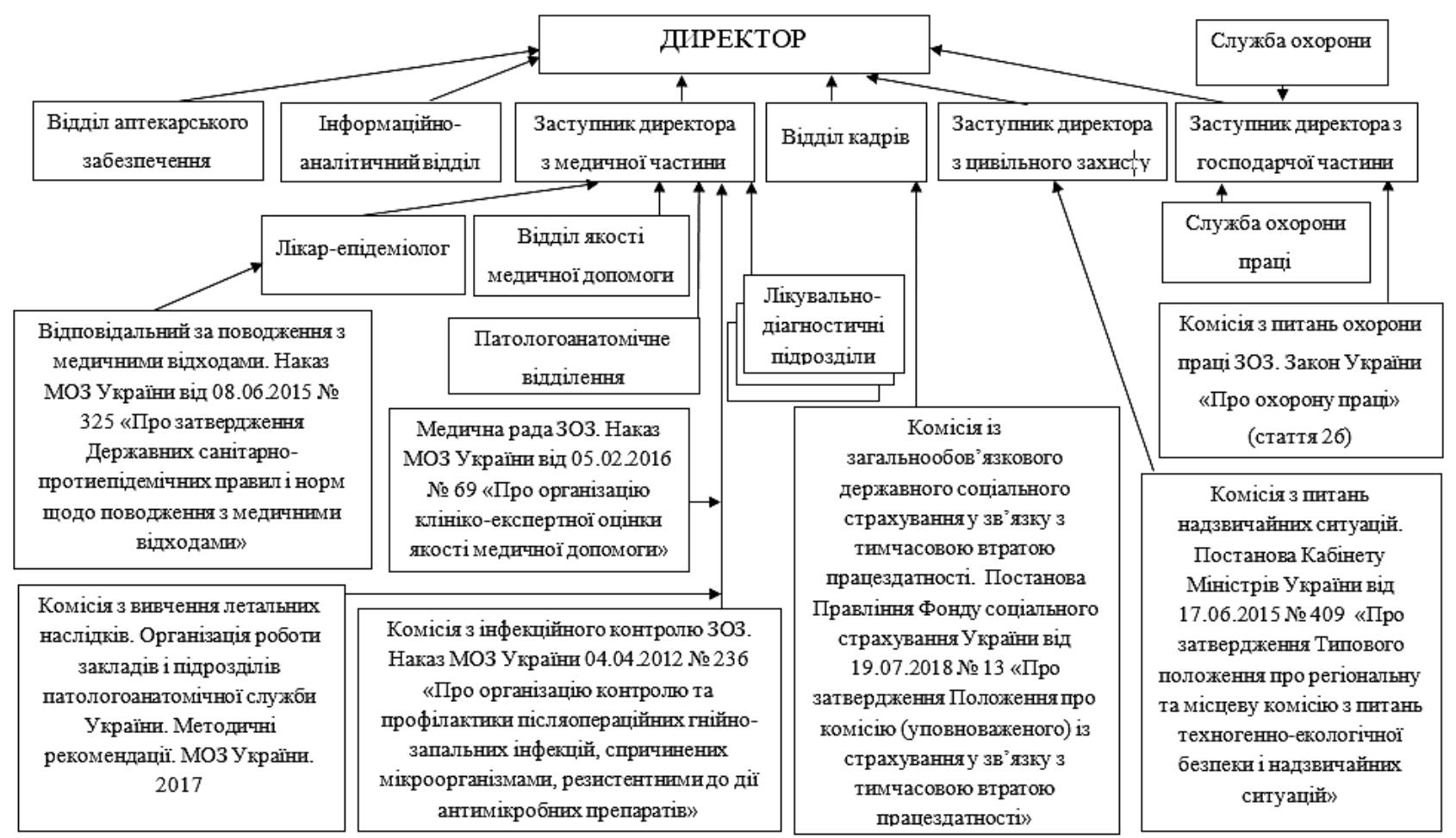

Рисунок 1. Структурно-функціональна схема існуючої системи (реактивної) забезпечення охорони праці медичних працівників, безпеки пацієнтів, екологічної безпеки.

Окремі характеристики безпекової сфери у досліджуваних 303

Таблиця 1

\begin{tabular}{|c|c|c|c|c|c|c|c|c|c|}
\hline \multirow[b]{2}{*}{ 尺े } & \multicolumn{9}{|c|}{ Окремі характеристики безпекової сфери закладів охорони здоров'я } \\
\hline & 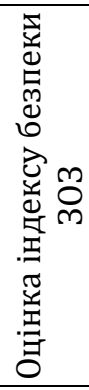 & 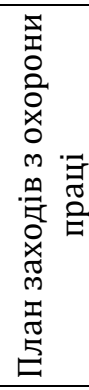 & 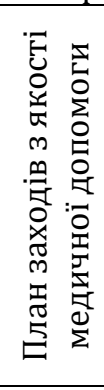 & 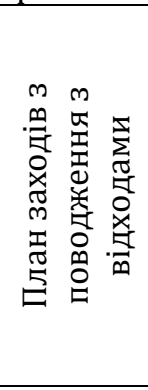 & 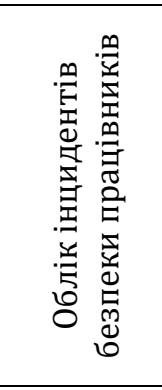 & 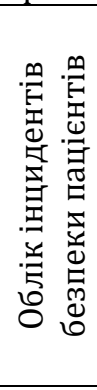 & 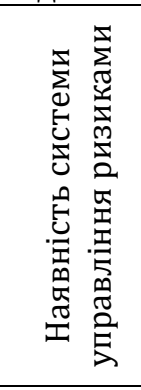 & 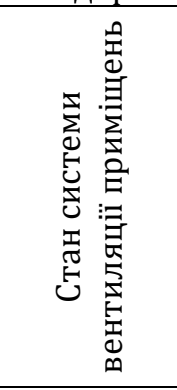 & 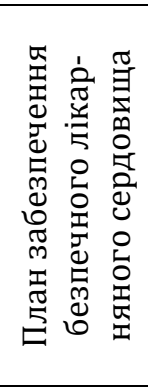 \\
\hline 1 & Так & Так & Так & Так & $\begin{array}{c}\text { На рівні } \\
\text { нещас- } \\
\text { них } \\
\text { випадків }\end{array}$ & Так* & $\mathrm{Hi}$ & $\begin{array}{c}\text { Венти- } \\
\text { ляція } \\
\text { окремих } \\
\text { примі- } \\
\text { щень } \\
\end{array}$ & $\mathrm{Hi}$ \\
\hline 2 & $\mathrm{Hi}$ & Так & Так & Так & $\begin{array}{c}\text { На рівні } \\
\text { нещас- } \\
\text { них } \\
\text { випадків }\end{array}$ & Так* & $\begin{array}{c}\text { Частко- } \\
\text { во }\end{array}$ & $\begin{array}{c}\text { Венти- } \\
\text { ляція } \\
\text { окремих } \\
\text { примі- } \\
\text { щень }\end{array}$ & $\mathrm{Hi}$ \\
\hline 3 & $\mathrm{Hi}$ & Так & Так & Так & $\begin{array}{c}\text { На рівні } \\
\text { нещас- } \\
\text { них } \\
\text { випадків }\end{array}$ & Так* & $\mathrm{Hi}$ & $\begin{array}{c}\text { Венти- } \\
\text { ляція у } \\
\text { робочому } \\
\text { стані }\end{array}$ & $\mathrm{Hi}$ \\
\hline 4 & $\mathrm{Hi}$ & Так & Так & Так & $\begin{array}{c}\text { На рівні } \\
\text { нещас- } \\
\text { них } \\
\text { випадків }\end{array}$ & Так* & $\mathrm{Hi}$ & $\begin{array}{c}\text { Венти- } \\
\text { ляція у } \\
\text { робочому } \\
\text { стані }\end{array}$ & $\mathrm{Hi}$ \\
\hline
\end{tabular}

*На рівні розходження патологоанатомічного і клінічного діагнозів 
Як бачимо із наведених на рис.1 даних, формально на забезпечення безпеки лікарняного середовища працює значна кількість структурних підрозділів, штатних і нештатних посадових осіб, дорадчих органів тощо. I це зрозуміло, оскільки 303 постановою Кабінету Міністрів України № 843 від 10.09.2008 р. визнані суб'єктами із значним ступенем ризику.

Традиційна практика організації діяльності 303 із забезпечення безпеки, передбачає надання керівником 303 відповідних повноважень 3 виконання контрольних функцій заступникам за окремими напрямами діяльності та завідувачам відділеннями / керівникам структурних підрозділів. Що стосується безпеки пацієнтів, то провідна роль тут належить внутрішньому контролю якості, який передбачає упровадження аудиту та самооцінювання системи управління якістю. Певна увага при цьому звертається на випадки дефектів, несприятливих наслідків лікування та скарги громадян, вивчення їх думки щодо отриманої медичної допомоги.

При цьому, функції контролю якості покладаються на всі лікувально-діагностичні підрозділи, найбільш важливими з яких $є$ патологоанатомічне відділення. Координує цю роботу відділ якості медичної допомоги.

Слід зазначити, що термінового поновлення з певними змінами та доповненнями потребує зліквідований у 2015 році наказ МО3 України від 12.05.1992 № 81 «Про розвиток та удосконалення патологоанатомічної служби в Україні», що на думку фахівців певною мірою позитивно могло вплинути на діяльність патологоанатомічних підрозділів в частині попередження дефектів надання медичної допомоги.

Ключовою фігурою в системі інфекційного контролю в $303 \epsilon$ штатний чи нештатний епідеміолог, а також комісія 3 інфекційного контролю лікарні (Наказ МОЗ України 04.04.2012 № 236).

Тривалий термін функціонування медичних рад 303, утворених відповідно до наказу МОЗ України від 05.02.2016 № 69 «Про організацію клініко-експертної оцінки якості медичної допомоги», показав, що їх діяльність зосереджена переважно на реагуванні на інциденти безпеки пацієнтів, а не на їх попередженні. Такий самий реактивний характер діяльності властивий аналогічним радам на рівні регіонів та МОЗ України.
Узагальнену інформацію щодо якості та безпеки медичної допомоги у 303 готує інформаційно-аналітичний підрозділ. При цьому, як правило, в частині безпеки пацієнтів надається лише інформація щодо випадків розходження клінічних і патологоанатомічних діагнозів, стаціонарної і післяопераційної летальності. Загалом, безпека пацієнтів як складова якості медичної допомоги у вітчизняній системі охорони здоров'я не позиціонується як важлива проблема [14].

Згідно Кодексу цивільного захисту України (2013) у 303 із загальною чисельністю працюючих та пацієнтів від 200 до 3000 осіб, передбачені посади фахівців 3 питань цивільного захисту, які зобов'язані проводити оцінки ризиків виникнення надзвичайних ситуацій у 303, здійснення заходів щодо неперевищення прийнятних рівнів таких ризиків. Відповідно до постанови Кабінету Міністрів України від 17.06.2015 №409 у суб'єктах господарської діяльності запроваджується робота комісії 3 питань надзвичайних ситуацій.

Про доцільність запровадження в Україні концепції індексу безпеки лікарень йдеться вже більше 10-ти років. Та, на жаль, в Україні така практика реалізується лише за вимоги міжнародних організацій при проведенні міжнародних заходів, наприклад, «вро-2012» чи окремих проектів (табл. 1).

Законом України «Про охорону праці» від 14.10.1992 № 2694-XII у закладах та установах з кількістю працюючих більше 50 осіб передбачається створення служби охорони праці. На цю службу покладається широке коло завдань від опрацювання ефективної системи управління охорони праці до проведення розслідування нещасних випадків, аналізу їх причин, а також організація навчання, інформування та надання роз'яснень працівникам з питань охорони праці. Як правило, служба охорони праці в 303 підпорядкована заступнику директора з господарчої частини. Відповідно до цього ж Закону у 303 утворюються також комісії з питань охорони праці.

Постановою Правління Фонду соціального страхування України від 19.07.2018 № 13 затверджено Положення про комісію (уповноваженого), на яку покладається облік осіб, що часто та довго хворіють. Аналіз такого обліку за категоріями працівників та причинами тимчасової непрацездатності складає основу для 
пропозицій 3 питань зниження рівня захворюваності.

Важлива роль в системі охорони праці нормативно-правовими документами відводиться профспілковим організаціям, але ця діяльність в нашій роботі не аналізується.

Згідно з наказом М03 України від 08.06.2015 № 325 у 303 призначається відповідальний за поводження 3 медичними відходами. Координація цієї діяльності покладається на штатного чи нештатного епідеміолога 303, а технічні питання на заступника директора з господарчої частини.

Діяльність служби охорони 303 також координується заступником директора 3 господарчої частини, хоч послуги з охорони, як правило, надаються охоронними комунальними підприємствами чи приватними фірмами.

Значні потоки нескоординованої, розрізненої, недостатньо грунтовно опрацьованої безпекової інформації від керівників підрозділів чи через заступників надходить на директора 303. При цьому йдеться як правило не про інциденти, які мають на увазі, перш за все, відхилення в роботі (умовах, процесах, поведінці) без шкоди для медичного персоналу, хворих та матеріальних цінностей, а лише про нещасні випадки (випадки травматизму, шкода здоров'ю і навіть життю пацієнтів, надзвичайні техногенні ситуації різної природи тощо).

Така інформація і такий порядок її представлення, на нашу думку, не можуть слугувати основою для опрацювання попереджувальних заходів, адекватних безпековій ситуації.

За таких умов кожна безпекова проблема розглядається як окрема і незалежна від інших (табл. 1). Проблеми якості медичної допомоги у вітчизняних 303, наприклад, пов'язують переважно 3 результатами лікувальнодіагностичної роботи. Інші ж чинники лікарняного середовища, такі, наприклад, як стан вентиляції, освітлення, шум тощо недооцінюються. Так, у 2-х з 4-х досліджуваних нами лікувальних закладах виявилось, що вентиляційна система десятиліттями практично не функціонує через відсутність коштів для підтримання i у робочому стані (табл.1). Така ситуація з вентиляцією певною мірою пояснює високу захворюваність медичного персоналу на COVID-19 і випадки, коли 303 були центрами вогнищ поширення цієї інфекції. За таких умов виникає немало питань щодо безпеки персоналу у лікарнях, що трансформовані у інфекційні в зв'язку 3 пандемією COVID-19.

Система управління ризиками формально запроваджується на вимоги фірм 3 акредитації 303 на відповідність ДСТУ ISO 9001:2015 (табл.1). За таких умов роль ризик орієнтованого підходу, як інструменту попередження інцидентів, практично нівелюється. В якості пропозицій щодо мінімізації ризиків пропонуються виключно організаційні заходи (табл.1), а потенціал інженерно-технічних рішень недооцінюється.

Спроб об'єднання проблем безпеки персоналу і пацієнтів в спільних планах чи програмах ми у досліджуваних 303 не виявили.

Тобто, діяльність системи охорони здоров'я і окремих 303 з питань безпеки орієнтована на реагування на нещасні випадки з медичним персоналом та дефекти медичної допомоги, що мають важкі наслідки для здоров'я чи навіть життя пацієнтів і, які, як правило, стаються не щоденно, а тому i безпека не вважається постійною проблемою. Загалом таку діяльність можна оцінити як формальну та недостатньо ефективну. Підтвердженням того є тенденції до зростання виробничого травматизму [15], а також рівнів стаціонарної та післяопераційної летальності у вітчизняних 303 [16].

\section{Шляхи формування проактивної системи забезпечення безпеки у 303}

Формування безпечного лікарняного середовища передбачає трансформацію існуючої реактивної системи охорони праці та безпеки пацієнтів 303, про яку згадувалося вище, у проактивну структуру, що забезпечить здорові та безпечні умови праці медичних фахівців, прийнятні ризики ненавмисної шкоди пацієнтам i мінімальний можливий негативний вплив лікарняного закладу на навколишнє середовище (рис.2).

Ключовим підрозділом такої структури має стати відділ управління ризиками, який створюється шляхом об'єднання всіх штатних одиниць і підрозділів, що мають безпосереднє відношення до безпеки, а саме: відділу якості медичної допомоги, служби охорони праці, лікаря-епідеміолога. Унаслідок такого об'єднання за умови належної підготовки співробітників формується дієздатний підрозділ чисельністю 3-4 штатні посади, спроможний здійснювати оцінку і управління ризиками, які існують постійно і вимагають постійної уваги до них. 


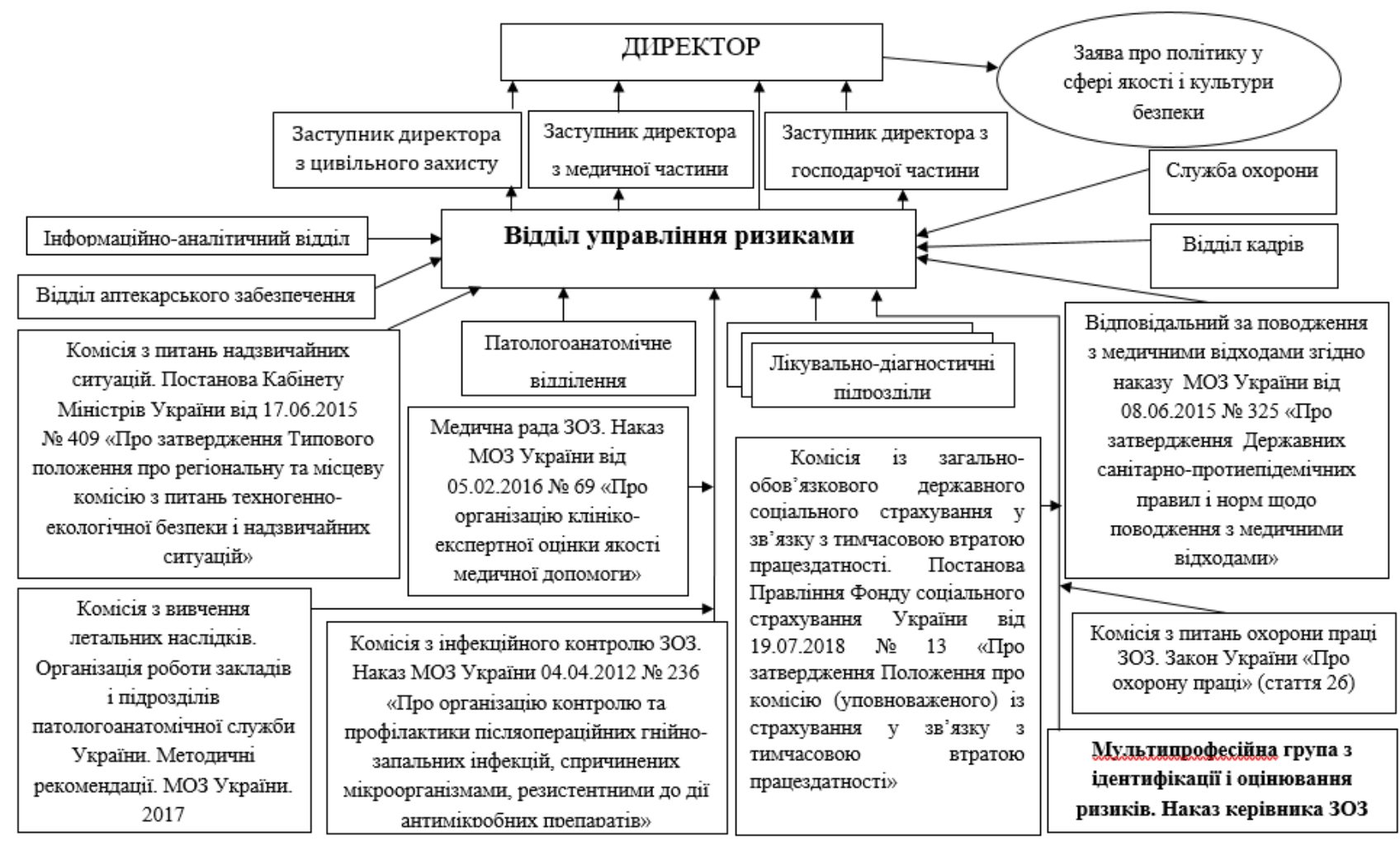

Рисунок 2. Запропонована структурно-функціональна схема проактивної системи забезпечення безпечного лікарняного середовища.

На цей новий підрозділ відповідно спрямовуватимуться всі інформаційні потоки, що стосуються безпеки медичного персоналу та пацієнтів, їх захищеності, захищеності майна 303 і джерел небезпеки від третіх осіб у повсякденних умовах і надзвичайних ситуаціях, а також інформації з екологічної безпеки. Першою передумовою успішного функціонування цього підрозділу є реєстрація не лише випадків виробничого травматизму i інцидентів безпеки пацієнтів 3 важкими наслідками для їх життя і здоров'я, але й майже подій (near-accidents) і майже помилок (near-misses). Важливим буде ідентифікація кореневих причин небезпечних подій, а не пошук осіб, причетних до їх виникнення. Тобто передумови запровадження ефективної системи управління ризиками. Виникне потреба в реальній роботі комісій, що мають відношення до формування безпечного лікарняного середовища.

Ідентифікація і оцінка ризиків здійснюватиметься мультипрофесійною (експертною, робочою) групою в складі представників 303 із можливим залученням зовнішніх експертів 3 питань управління ризиками. Така група збирається, як правило, 1-2 рази на рік або у випадку принципової зміни безпекової ситуації [17 -18].
Нова структура за умови формування належної культури безпеки з упровадженням системи управління ризиками розвантажить керівництво 303 від фрагментарної безсистемної безпекової інформації, дозволить відранжувати небезпеки за рівнем ризику, дати інформацію для проведення оптимальних за вартістю та ефективністю безпекових заходів, забезпечить умови для оцінки та моніторингу ризиків за єдиними підходами, створить передумови для запровадження проактивного підходу в сфері охорони праці, безпеки пацієнтів, екологічної безпеки, а також реагування на надзвичайні ситуації.

Поінформованість керівництва в безпековій сфері, зрозумілість і керованість безпекового середовища сприятимуть підвищенню інтересу до питань безпеки всіх працівників i, відповідно, формуванню належної організаційної культури та культури безпеки в 303 [19-20].

Важливим моментом демонстрації лідерства у формуванні культури безпеки через тісну інтеграцію питань безпеки пацієнтів та медичного персоналу інших без пекових проблем вважається заява керівництва 303 про політику у сфері якості та культури безпеки медичної діяльності [21]. 


\section{Висновки}

1. Інтеграція питань безпеки пацієнтів та безпеки медичного персоналу у єдиних програмах є стратегічним напрямом і кращою практикою у формуванні безпечного лікарняного середовища в Європі і має бути реалізована в нашій країні.

2. Багато елементів або дій із забезпечення безпеки за різними напрямами мають єдину мету - захист людей, суспільства й навколишнього середовища від потенційно негативного впливу діяльності лікарняних закладів, і спираються практично на єдині принципи забезпечення такого захисту. Заходи за одним напрямом підсилюють інші й забезпечують ефект синергізму як результат формування культури безпеки.

3. Вітчизняна нормативна база і практика передбачають автономне та роздільне

\section{Література}

1. The safety of nuclear power. INSAG-5. International Atomic Energy Agency. Vienna. 1992. URL : https://www-pub.iaea.org/MTCD/ publications/PDF/Pub910e web.pdf

2. Взаимосвязь между безопасностью и физической безопасностью на атомных электростанциях. INSAG-24. МАГАТЭ, Вена, 2014. $34 \mathrm{c}$.

3. Sikorski Joseline. Connecting worker safety to patient safety: a new imperative for health-care leaders. Ivey Business journel. Is.: January / February 2009. URL : https://iveybusinessjournal.com /publication/connecting-worker-safety-to-patientsafety-a-new-imperative-for-health-care-leaders/

4. Braun B. Improving Patient and Worker Safety. Barbara Braun, Annette Riehle, Kris Donofrio, Hasina Hafiz, Jerod M. Loeb et al. 2012. URL : https://www.jointcommission.org/assets/1/18/TJC ImprovingPatientAndWorkerSafety-Monograph.pdf

5. Environment of Care Management Plans. Revised. 07/2017. URL : https://riversidecountyca. iqm2.com

6. Interaction of Health Care Worker Health and Safety and Patient Health and Safety in the US Health Care System: Recommendations From the 2016 Summit. ACOEM position statement. ACOEM position statement. Ronald Loeppke, Jodie Boldrighini, John Bowe, Barbara Braun, Erik Eggins et al. J Occup Environ Med. 2017. Aug. URL : https://pubmed.ncbi. nlm.nih.gov/28796664/

7. The Tokyo Declaration on patient safety. BMJ 2018; 362 doi: https://doi.org/10.1136/bmj.k3424 (Published 08 August 2018)Cite this as: BMJ 2018;362:k3424

8. Patient Safety Strategy 2019-2024. Quality Assurance and Verification, Office of the Chief Clinical Officer, Health Service Executive. Dublin. 2019. URL : https://www.hse.ie/eng/about/qavd/patientsafety/hse-patient-safety-strategy-2019-2024.pdf; вирішення безпекових проблем щодо пацієнтів, медичного персоналу і оточуючого середовища і вимагають перегляду.

4. Управління ризиками як грунтовний всебічний підхід до вирішення безпекових проблем у сучасних лікарняних закладах практикується лише в окремих із них і скоріше на формальному рівні без детального аналізу ситуації та визначенням кореневих причин проблем.

5. Трансформація структури і функцій підрозділів закладів охорони здоров'я, задіяних у забезпеченні безпеки пацієнтів, медичного персоналу, екологічної безпеки, за єдиною узгодженою стратегією сприятиме формуванню безпечного лікарняного середовища на засадах культури безпеки.

9. Safer Together A National Action Plan to Advance Patient Safety. Institute for Healthcare Improvement. $2020 . \quad$ URL

https://f.hubspotusercontent30.net/hubfs/241684/N ational\%20Action \%20Plan\%20(NAP)/IHI-

NSC SaferTogetherNationalActionPlantoAdvancePatie ntSafety.pdf?utm campaign=National\%20Action $\% 20 \mathrm{P}$ lan\%20\&utm source=Thank you\&utm content=Safety Action Plan

10.Глобальные действия по обеспечению безопасности пациентов. Доклад Генерального директора. В03. Исполнительный комитет. 148-я сессия. EB148/6. 2021. URL : https://apps.who.int/gb/ebwha/pdf files/EB148/B1 486-ru.pdf

11.Rahul K. Patient Safety and Quality Improvement in Healthcare. A Case-Based Approach. K.Rahul, A.Shah Sandip, Switzerland. Sprsnger. 2021. URL : $\quad \underline{\text { https://link.springer.com/book }}$ /10.1007\%2F978-3-030-55829-1

12. Shaw Alexandra. No patient safety without health worker safety. Alexandra Shaw, Kelsey Flott, Gianluca Fontana, Mike Durkin, Ara Darzi. Lancet. 2020. Nov 14;396(10262):1541-1543. doi: 10.1016/S01406736(20)31949-8. URL https://pubmed.ncbi.nlm.nih.gov/32949501/

13. Seven steps to patient safety. The full reference guide. Second print / National Patient Safety Agency. - August 2004. - P.- 188. Internet: URL : http://www.nrls.npsa.nhs.uk/EasySiteWeb/getresour ce.axd?AssetID=59971

14.Питання безпеки хворих у системі забезпечення якості надання медичної допомоги / А. М. Сердюк, М. М. Риган, О. М. Науменко, І. К. Асаулюк, Ю. М. Скалецький // Врачебное дело. - № 1-2 (1141) / Январь - февраль 2017 г. / Киев, ИНЦ «Лікарська справа, 2017. - С. 149-155.

15.Сердюк А. М. Виробничий травматизм в медичній галузі: стан і тенденції / O. П. 
Яворовський, Ю. М. Скалецький, М. М. Риган, В. В. Майстренко // Журнал Національної академії медичних наук України. - 2017. - № 3-4. - С. 47-54.

16.Скалецький Ю. М. Тенденції стаціонарної та післяопераційної летальності як показників безпеки пацієнтів в Україні. Ю. М. Скалецький, О. П. Яворовський, С. Г. Гичка, М. М. Риган, В. Л. Дідковський, Р. П. Брухно. Український медичний часопис. 3 (137), T. 2 - V/VI 2020. С. 38-41

17. Kaya G. K., Ward I. R., Clarkson P. I. A framework to support risk assessment in hospitals. International Journal for Quality in Health Care.V. 31, I. 5, June 2019, P. 393-401. URL : https://doi.org/10.1093/intqhc/mzy194;

18. Wagner C., Merten H., Zwaan L., Lubberding S. Unit-based incident reporting and root cause analysis: variation at three hospital unit types. BMJ Open. 2016, Jun 21;6(6):e011277. doi : 10.1136/bmjopen-2016011277.

\section{References}

1. The safety of nuclear power. (1992). INSAG-5. International Atomic Energy Agency. Vienna. URL : https://www-

pub.iaea.org/MTCD/publications/PDF/Pub910e_web. pdf.

2. Vzaimosvyaz mezhdu bezopasnostyu i fizicheskoy bezopasnostyu na atomnyih elektrostantsiyah. (2014). INSAG-24. MAGATE, Vena. 34.

3. Sikorski Joseline. (2009). Connecting worker safety to patient safety: a new imperative for healthcare leaders. Ivey Business journel. Is.: URL : https://iveybusinessjournal.com/publication/connect ing-worker-safety-to-patient-safety-a-new-

imperative-for-health-care-leaders.

4. Barbara Braun, Annette Riehle, Kris Donofrio, Hasina Hafiz, Jerod M. Loeb et al. (2012). Improving Patient and Worker Safety. URL : https://www.jointcommission.org/assets/1/18/TJC ImprovingPatientAndWorkerSafety-Monograph.pdf

5. Environment of Care Management Plans. Revised. $\quad 07 / 2017 . \quad$ URL https://riversidecountyca.iqm2.com.

6. Ronald Loeppke, Jodie Boldrighini, John Bowe, Barbara Braun, Erik Eggins et al. Interaction of Health Care Worker Health and Safety and Patient Health and Safety in the US Health Care System: Recommendations From the 2016 Summit. (2017). ACOEM position statement. ACOEM position statement. J Occup Environ Med. URL

https://pubmed.ncbi.nlm.nih.gov/28796664.

7. The Tokyo Declaration on patient safety. (2018). BMJ; 362 doi: https://doi.org/10.1136/bmj.k3424. Cite this as: BMJ 2018;362:k3424.

8. Patient Safety Strategy 2019-2024. (2019). Quality Assurance and Verification, Office of the Chief Clinical Officer, Health Service Executive. Dublin. URL : https://www.hse.ie/eng/about/qavd/patientsafety/hse-patient-safety-strategy-2019-2024.pdf;
19.Boo Y. K., Lee H. S., Park J. W., Ham S. W. Identifying Organizational Culture for Patient Safety. International Conference on Grid and Distributed Computing. URL : https://link.springer.com/chapter/ 10.1007/978-3-642-27180-9 33;

20. Monteiro da Silva N. D., Barbosa, A. P., Padilha K. G., Malik A. M. Patient safety in organizational culture as perceived by leaderships of hospital institutions with different types of administration. Rev. esc. enferm. USP vol.50 no.3 São Paulo May/June 2016. URL : $\quad$ https://doi.org/10.1590/S0080$\underline{623420160000400016}$

21. Культура безопасности. Серия изданий по безопасности, № 75-INSAG-4. Доклад Международной консультативной группы по ядерной безопасности. Международное агентство по атомной энергии. Вена, 1991. URL : https://www.sunpp.mk.ua/sites/default/files/docum ents/INSAG4_rus.pdf.

9. Safer Together (2020). A National Action Plan to Advance Patient Safety. Institute for Healthcare Improvement. URL

'https://f.hubspotusercontent30.net/hubfs/241684/N ational\%20Action\%20Plan\%20(NAP)/IHI-

NSC SaferTogetherNationalActionPlantoAdvancePatie ntSafety.pdf?utm_campaign=National\%20Action $\% 20 \mathrm{P}$ lan\%20\&utm source=Thank you\&utm content=Safety Action Plan.

10. Globalnyie deystviya po obespecheniyu bezopasnosti patsientov. (2021). Doklad Generalnogo direktora. VOZ. Ispolnitelnyiy komitet. 148-ya sessiya. EB148/6. URL https://apps.who.int/gb/ebwha/pdf_files/EB148/B1 48_6-ru.pdf.

11. Rahul, K. (2021). Patient Safety and Quality Improvement in Healthcare. A Case-Based Approach. K.Rahul, A.Shah Sandip, Switzerland. Sprsnger. URL : https://link.springer.com/book/ 10.1007\%2F978-3-030-55829-1.

12. Alexandra Shaw, Kelsey Flott, Gianluca Fontana, Mike Durkin, Ara Darzi. (2020). No patient safety without health worker safety. Lancet. 14; 396 (10262): 1541-1543. doi: 10.1016/S01406736(20)31949-8. URL https://pubmed.ncbi.nlm.nih.gov/32949501.

13. Seven steps to patient safety. The full reference guide. Second print. (2004). National Patient Safety Agency. 188. Internet: URL : http://www.nrls.npsa.nhs.uk/EasySiteWeb/getresour ce.axd?AssetID $=59971$

14. Serdyuk, A. M., Rigan, M. M., Naumenko, O. M., Asaulyuk, I. K., Skaletskiy, Yu. M. (2017). Pitannya bezpeki hvorih u sistemI zabezpechennya yakostI nadannya medichnoYi dopomogi. Vrachebnoe delo. 12 (1141). Kiev, INTs «Likarska sprava, 149-155.

15. Serdyuk, A. M. Yavorovskiy, O. P., Skaletskiy, Yu. M., Rigan, M. M., Maystrenko, V. V. (2017). Virobnichiy travmatizm $\mathrm{v}$ medichnIy galuzI: stan $\mathrm{i}$ 
tendentsiyi. Zhurnal NatsIonalnoyi akademiyi medichnih nauk Ukrayini. 3-4. 47-54.

16. Skaletskiy Yu. M. Yavorovskiy, O. P., Gichka, S. G., Rigan, M. M., Didkovskiy, V. L., Bruhno, R. P. Tendentsiyi statsionarnoy ta pislyaoperatsiynoyi letalnosti yak pokaznikIv bezpeki patsientiv v Ukrayini. (2020).. Ukrayinskiy medichniy chasopis. 3 (137), T. 2 V/VI. S. 38-41.

17. Kaya, G. K. , Ward, J. R. , Clarkson, P. J. (2019). A framework to support risk assessment in hospitals. International Journal for Quality in Health Care.V. 31, I. 5 , $P$. 393-401.

URL : https://doi.org/10.1093/intqhc/mzy194;

18. Wagner, C., Merten, H., Zwaan, L., Lubberding, S. (2016). Unit-based incident reporting and root cause analysis: variation at three hospital unit types. $B M J$ Open. 21;6(6):e011277. doi: 10.1136/bmjopen-2016011277.

19. Boo, Y. K., Lee, H. S., Park, J. W., Ham, S. W. Identifying Organizational Culture for Patient Safety.
International Conference on Grid and Distributed Computing. URL https://link.springer.com/chapter/10.1007/978-3642-27180-9 33.

20. Monteiro da Silva, N. D., Barbosa, A. P., Padilha, K. G., Malik, A. M. (2016). Patient safety in organizational culture as perceived by leaderships of hospital institutions with different types of administration. Rev. esc. enferm. USP. vol.50 no.3 São Paulo MayURL : https://doi.org/10.1590/S0080623420160000400016.

21. Kultura bezopasnosti. (1991). Seriya izdaniy po bezopasnosti, \# 75-INSAG-4. Doklad Mezhdunarodnoy konsultativnoy gruppyi po yadernoy bezopasnosti. Mezhdunarodnoe agentstvo po atomnoy energii. Vena, URL https://www.sunpp.mk.ua/sites/default/files/docum ents/INSAG4_rus.pdf.

\title{
СИСТЕМА ОБЕСПЕЧЕНИЯ БЕЗОПАСНОСТИ ПЕРСОНАЛА И ПАЦИЕНТОВ В БОЛЬНИЧНОМ УЧРЕЖДЕНИИ: СТРАТЕГИЯ СОВЕРШЕНСТВОВАНИЯ
}

\section{О.П. Яворовский ${ }^{1}$, М.М. Риган ${ }^{2}$, О.В. Иванько ${ }^{3}$, Ю.М. Скалецкий ${ }^{1,4}$, Р.П. Брухно1, П.М. Михайленко4 ${ }^{4}$ Т.о. Зинченко1, М.И. Бадюк5}

\author{
${ }_{1}^{1}$ Национальный медицинский университет имени А.А. Богомольца, г. Киев, Украина \\ ${ }^{2}$ Центр спортивной травматологии и восстановительной медицины Национального университета \\ физического воспитания и спорта Украины, г. Киев, Украина \\ ${ }^{3}$ КНП «Киевская городская клиническая больнища №1 Исполнительного органа Киевского городского \\ совета (КГГА)», г. Киев, Украина \\ ${ }^{4}$ ДУ «Институт общественного здоровья им. А.Н. Марзеева НАМН Украины», г. Киев, Украина \\ 5 Украинская военно-медицинская академия, г. Киев, Украина
}

Цель: оценить состояние интегрированности вопросов безопасности пациентов и безопасности медицинского персонала в отечественных лечебных учреждениях, рассмотреть возможности усиления их взаимосвязи и взаимовлияния в пользу минимизации рисков больничной среды.

Материалы и методы. Проанализированы декларации, стратегии ВОЗ, отдельных стран, другие документы и тематические научные публикации. Исследовано отечественную нормативную базу и частично практику формирования безопасной больничной среды в 4-х учреждениях. Методы исследований: библиосемантический, гигиенический, системного подхода, аналитический, статистические и математические.

Результаты. Оценено состояние интегрированности вопросам безопасности пациентов и безопасности медицинского персонала в отечественных лечебных учреждениях. Установлено, что предупреждение случаев производственного травматизма и инцидентов безопасности пациентов в отечественных лечебных учреждениях осуществляется автономно по разным планам и программам и неэффективно, о чем свидетельствует рост как несчастных случаев в отечественных лечебных учреждениях, так и стационарной $u$ послеоперационной летальности. Предложены подходы $\kappa$ трансформации структуры и функций безопасности подразделений учреждений здравоохранения с целью формирования безопасного больничного среды на основе культуры безопасности.

Выводы. Интеграция вопросов безопасности пациентов и безопасности медицинского персонала в единых программах является стратегическим направлением и лучшей практикой в формировании безопасной больничной среды за рубежом и ее целесообразно внедрять в нашей стране. Отечественная нормативная база и практика предусматривает автономное и раздельное решения проблем безопасности пациентов, медицинского персонала и окружающей среды. Трансформация структуры и функций подразделений учреждений здравоохранения, задействованных в обеспечении безопасности пациентов, медицинского персонала, экологической безопасности, по единой согласованной стратегии будет способствовать формувнню безопасной больничной среды на основе культуры безопасности.

Ключевые слова: безопасности пациентов, безопасность и гигиена труда медицинского персонала, интеграция, учреждения здравоохранения, культура безопасности. 


\title{
THE SYSTEM OF SAFETY SUPPORT FOR STAFF AND PATIENTS IN HOSPITALS: IMPROVEMENT STRATEGY
}

\author{
O.P. Yavorovsky1, M.M. Rygan², O.V. Ivanko3 ${ }^{3}$, Yu.M. Skaletsky ${ }^{1,4}$, \\ R.P. Brukhno1, P.M. Mykhaylenko4, T.O. Zinchenko', M.I. Badiuk ${ }^{5}$
}

${ }^{1}$ Bogomolets National Medical University, Kyiv, Ukraine

${ }^{2}$ Center for Sports Traumatology and Rehabilitation Medicine of the National University of Physical Education and Sport of Ukraine, Kyiv, Ukraine

${ }^{3}$ KNP «Kyiv City Clinical Hospital №1 of the Executive Body of the Kyiv City Council», Kyiv, Ukraine

${ }^{4} S I$ «Institute of Public Health named afte O.N. Marzeev of National Academy of Medical Sciences of Ukraine», Kyiv, Ukraine

${ }^{5}$ Ukrainian Military Medical Academy, Kyiv, Ukraine

The purpose: to assess the state of integration of patient safety and safety of medical staff in domestic hospitals and consider ways to strengthen their relationship and interaction in order to minimize the risks of the hospital environment.

Material and methods. Analyzed declarations, WHO strategies, individual countries, other documents and thematic scientific publications. The domestic regulatory framework and partially the practice of forming a safe hospital environment in 4 health care facilities have been studied. Research methods: bibliosemantic, hygienic, systems approach, analytical, statistical and mathematical.

Results. The state of integration of issues of patient safety and safety of medical staff in domestic hospitals is assessed. It has been established that the prevention of occupational injuries and patient safety incidents in domestic hospitals is carried out autonomously according to various plans and programs and is ineffective, as evidenced by the growth of accidents in domestic hospitals and inpatient and postoperative mortality. Approaches to the transformation of the structure and functions of security units of health care facilities in order to create a safe hospital environment based on safety culture are proposed.

Conclusions. The integration of patient safety and safety of medical staff in single programs is a strategic direction and best practice in creating a safe hospital environment abroad and it is advisable to implement it in our country. Domestic regulations and practices provide for autonomous and separate solutions to safety problems for patients, medical staff and the environment. Transformation of the structure and functions of the units of health care institutions involved in ensuring the safety of patients, medical staff, environmental safety, according to a single agreed strategy will contribute to the formation of a safe hospital environment based on safety culture.

Key words: patient safety, occupational safety and health, integration, health care facilities, safety culture.

Конфлікт інтересів: відсутній.

Conflictsofinterest:authorshavenoconflictofinteresttodeclare.

Відомості про авторів:

Яворовський О.П. А,B,C,D,E, - доктор медичних наук, професор, академік НАМН України, завідувач кафедри гігієни та екології №2 Національного медичного університету імені 0.0. Богомольця, м. Київ.

Риган М.М. А,B,C,D - к.мед.н., директор Центру спортивної травматології та відновлювальної медицини Національного університету фізичного виховання і спорту України, Київ.

Іванько О.В. А,B,C,D - к.мед.н., директор КНП «Київська міська клінічна лікарня №1 Виконавчого органу Київської міської ради (КМДА)», Київ.

Скалецький Ю.М. А,B,C,D,E,F - доктор медичних наук, професор, завідувач лабораторії безпекових стратегій в охороні здоров'я ДУ «Інститут громадського здоров'я ім. О.М. Марзєєва НАМН України», професор кафедри гігієни та екології №2 Національного медичного університету імені 0.0. Богомольця, м. Київ.

Брухно Р.П. А,B,C,D,E - к.мед.н., асистент кафедри гігієни та екології №2 Національного медичного університету імені О.О. Богомольця, м. Київ.

Михайленко П.М. В,С,D - к.біолог.н., старший науковий співробітник лабораторії безпекових стратегій в охороні здоров'я ДУ «Інститут громадського здоров’я ім. О.М. Марзєєва НАМН України», Київ

Зінченко T.о. C,D - к.мед.н., доцент кафедри гігієни та екологї №2 Національного медичного університету імені О.О. Богомольця, м. Київ.

Бадюк М.I. ${ }^{E}$ - доктор медичних наук, професор, начальник кафедри організації медичного забезпечення збройних сил Української військово-медичної академії, м. Київ.

$A$ - концепція та дизайн дослідження; $B$ - збір даних; $C$ - аналіз та інтерпретація даних;

$D$ - написання статmi; E- редагування cmammi; F- остаточне затвердження статті 
Сведения об авторах:

Яворовский А.П. А, В, с, D, Е, F - доктор медицинских наук, профессор, академик НАМН Украины, заведующий кафедрой гигиены и экологии №2 Национального медицинского университета имени А.А. Богомольца, г. Киев.

Риган М.М. А, В, С, D - к.м.н., директор Центра спортивной травматологии и восстановительной медицины Национального университета физического воспитания и спорта Украины, Киев.

Иванько А.В. А, в, с, D - к.м.н., директор КНП «Киевская городская клиническая больница №1 Исполнительного органа Киевского городского совета (КГГА)», Киев.

Скалецкий Ю.Н. А, B, C, D, E, F - доктор медицинских наук, профессор, заведующий лабораторией безопасности стратегий в здравоохранении ГУ «Институт общественного здоровья им. А.Н. Марзеева НАМН Украины», профессор кафедры гигиены и экологии №2 Национального медицинского университета имени А.А. Богомольца, г. Киев.

Брухно Р.П. А, В, C, D, E - к.м.н., ассистент кафедры гигиены и экологии №2 Национального медицинского университета имени А.А. Богомольца, г. Киев.

Михайленко П.М. В, С, D - к.биолог.н., Старший научный сотрудник лаборатории безопасности стратегий в здравоохранении ГУ «Институт общественного здоровья им. А.Н. Марзеева НАМН Украины «, г. Киев.

Зинченко T.A. C, D - к.м.н., доцент кафедры гигиены и экологии №2 Национального медицинского университета имени А.А. Богомольца, г. Киев.

Бадюк М.И. Е - доктор медицинских наук, профессор, начальник кафедры организации медицинского обеспечения вооруженных сил Украинской военно-медицинской академии.

Information about the authors:

Yavorovsky A.P. A, B, C, D, E, F - Doctor of Medical Sciences, Professor, Academician of the National Academy of Medical Sciences of Ukraine, Head of the Department of Hygiene and Ecology №2 of the Bogomolets National Medical University, Kyiv, https://orcid.org/0000-0002-4573-8039.

Rygan M.M. A, B, C, D - Candidate of Medical Sciences, Director of Center for Sports Traumatology and Rehabilitation Medicine of the National University of Physical Education and Sport of Ukraine, Kyiv, https://orcid.org/0000-0003-1244-9801.

Ivanko A.V. A, B, C, D - Candidate of Medical Sciences, Director of the Kyiv City Clinical Hospital №1 of the Executive Body of the Kyiv City Council (Kyiv City State Administration), Kyiv, https://orcid.org/0000-0002-70157340 .

Skaletsky Yu.N. A, B, C, D, E, F - doctor of medical sciences, professor, head of the laboratory of safety strategies in health care of the State Institution «Institute of Public Health named afte O.N. Marzeev of National Academy of Medical Sciences of Ukraine», Professor of the Department of Hygiene and Ecology №2 of the National Medical University named after A.A. Bogomolets, Kyiv, https://orcid.org/0000-0001-7527-6827.

Brukhno R.P. A, B, C, D, E - Candidate of Medical Sciences, Assistant of the Department of Hygiene and Ecology №2 of the Bogomolets National Medical University, Kyiv, https://orcid.org/0000-0002-6666-397X.

Mikhailenko P.M. B, C, D - Candidate of Biological Sciences, Senior Researcher of the Laboratory of Safety Strategies in Health Care, State Institution «Institute of Public Health named afte O.N. Marzeev of National Academy of Medical Sciences of Ukraine», Kyiv, https://orcid.org/0000-0002-4802-2407.

Zinchenko T.A. C, D - Candidate of Medical Sciences, Associate Professor of Hygiene and Ecology №2 of the Bogomolets National Medical University, Kyiv, https://orcid.org/0000-0002-6652-2800.

Badiuk M.I. E - doctor of medical sciences, professor, Ukrainian Military Medical Academy, Kyiv, E-mail: badiuk@ukr.net, https://orcid.org/0000-0002-2995-0910

$A$ - research concept and design; $B$ - collection and/or assembly of data; $C$ - data analysis and interpretation;

$D$ - writing the article; $E$ - critical revision of the article; $F$ - final approval of the article.

Адреса для листування: бульвар Тараса Шевченка, 13, Україна, Київ, 01601

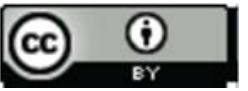

